\title{
Chapter 8 \\ Women in South Africa: Striving \\ for Full Equality Post-apartheid
}

\author{
Judith L. Gibbons, Katelyn E. Poelker and Mokgadi Moletsane-Kekae
}

You strike the women, you strike the rock.

-(South African History Archive, 2016)

The quote that leads this chapter is the title of a famous resistance song of the 1950s. It emphasizes the resilience and courage of South African women and thus represents an appropriate introduction to our topic and the theme throughout the chapter. In other words, although women in South Africa face many challenges, they are strong, brave, and resilient.

The population of South Africa is extremely diverse; people differ not only by gender but also by language (11 are recognized), race, religion, ethnic community, rural-urban residence, age, health status, and economic condition. With respect to economic conditions, the Gini coefficient, a measure of economic disparity, is one of the highest in the world (Bhorat 2015; World Bank 2016). Any discussion of gender inequalities and the status of women in South Africa must acknowledge the history and legacy of apartheid, as well as socioeconomic and racial disparities among women (Mayer and Barnard 2015). The concept that the dimensions on which women differ-race, culture, age, and economic condition-lead to specific conditions for intersecting groups is often known as intersectionality.

Individual South African women may experience very different worlds. One of the richest women in South Africa is Mamphela Ramphele, a former activist against apartheid, mother, politician, medical doctor, and the recipient of many honorary

\footnotetext{
J.L. Gibbons $(\bowtie) \cdot$ K.E. Poelker

Department of Psychology, Saint Louis University, 3700 Lindell Blvd,

Saint Louis, MO 63103, USA

e-mail: gibbonsj1@slu.edu

K.E. Poelker

e-mail: kpoelke1@slu.edu

M. Moletsane-Kekae

E104 Faculty of Education, Robert Sobukwe, University of the Western Cape,

Bellville, Cape Town 7535, South Africa

e-mail: moletsane@gmail.com
} 
degrees. She is said to be worth at least USD \$50 million (Nedu, n.d.). On the other hand, Mkhwanazi is a 19-year-old head of household whose mother died when she was 13 . She has been the primary caregiver for two younger sisters and a brother. Although she hopes to study nursing in Johannesburg, she does not command the necessary financial resources (Underhill 2015). Thus, it is difficult to generalize about the "typical" South African woman given that race and financial resources greatly influence a woman's life circumstances and status in society.

The legal framework for gender equality in South Africa is well established. The post-apartheid Constitution of 1996 is one of the most progressive in the world and guarantees rights to dignity, equality, culture, and language. The constitution prohibits direct or indirect discrimination on the basis of "race, gender, sex, pregnancy, marital status, ethnic or social origin, color, sexual orientation, age, disability, religion, conscience, belief, culture, language and birth" (Government of South Africa 1996).

However, there are inherent tensions in the rights guaranteed by South Africa's constitution. Although women are guaranteed equal rights with men, cultural (both individual and community) rights are also recognized. Because most traditional cultural groups in South Africa are patriarchal, with women considered to be the property of men, traditional customs still leave many women poor, vulnerable, and suffering from discrimination (Bower 2014). Mubangizi (2012) has outlined traditional practices that may conflict with women's rights. Among customary practices are female circumcision, virginity testing, ukuthwala (marriage by abduction), lobola (bride price), and polygamy. He argues that all of these practices violate the principles of equality because they unequally impact women and their dignity; he recommends education and advocacy to effect elimination of these practices. Customary (indigenous) law also favored sons and other male relatives with respect to inheritance. Although the South African courts have ruled that laws specifying male primogeniture are unconstitutional (Grant 2006), rural women continue to fight for the right of land ownership (Claassens and Mnisi 2009).

\section{Education of Girls and Women}

Understanding the educational opportunities afforded to a country's girls and women reveals a great deal about their potential for success. Since South Africa's Schools Act was instituted in 1996, education has been compulsory for both boys and girls from ages 7 to 15 (Statistics South Africa 2011). Despite the government's large expenditure on education, children and adolescents encounter many barriers to school attendance (UNICEF South Africa, n.d.b). For girls, these barriers are often related to the violence and abuse they experience at home (UNICEF South Africa, n.d.a). Teenage pregnancy and other issues pertaining to sexual health are other obstacles for girls' attendance and continued enrollment in school (UNICEF South Africa, n.d.a).

In spite of those barriers, however, enrollment statistics are quite good; almost all South African children ages 7-15 are enrolled in school regardless of gender 
(Timæus et al. 2013), and nearly all youth ages 15-24 are literate (99.2\% of young women and $98.4 \%$ of young men). The country boasts a high overall literacy rate with $93 \%$ of women and $96 \%$ of men able to read and write (World Economic Forum 2015). In fact, South Africa has reached gender parity with respect to school enrollment (ONE 2015). Eighty-nine percent of girls are enrolled in primary school compared to $90 \%$ of boys (World Economic Forum 2015). At both the secondary and tertiary levels, $69 \%$ of South African girls are enrolled in secondary school compared to $62 \%$ of boys (World Economic Forum 2015). At the tertiary level, 23\% of women are enrolled in university, compared to $17 \%$ of men (World Economic Forum 2015). The high rates of school enrollment through secondary school could be due, in part, to the low rates of adolescent marriage (UNICEF 2013), suggesting there may be an overall cultural value that supports girls' education. More specifically, only $3.6 \%$ of adolescent girls are married (UNICEF 2013).

Unfortunately, though, for some girls, enrollment does not translate into graduation from secondary school. Many of the same challenges discussed earlier, like adolescent pregnancy, force some girls to drop out of school (Moeti 2012). Additional barriers like inadequate access to feminine hygiene products cause some girls to regularly miss significant class time (Moletsane 2011). These obstacles present unique challenges for female students and are, of course, compounded by poverty. Nevertheless, in 2011, more girls graduated from secondary school than boys; $48.1 \%$ of girls completed high school compared to only $39.8 \%$ of boys (Statistics South Africa 2013).

Furthermore, for both genders, considerable racial disparities exist with respect to high school completion as nearly all White $(87.1 \%)$ and Asian $(83.8 \%)$ youth graduated from secondary school in 2011 in contrast to less than half of Black African (39.7\%) and "Colored" (43.9\%) youth (Statistics South Africa 2013). Those statistics serve as an ever-present reminder that great disparities persist in the country depending on race and socioeconomic status.

Several organizations in South Africa are dedicated to ensuring a safe educational environment for girls to counteract risks such as a long distance between the girls' homes and their schools and the absence of separate bathrooms for boys and girls. For example, the Girls Education Movement is a continent-wide initiative that promotes the education of girls by protecting them in their school environments by addressing conditions that make sexual assault in schools likely (Anzia 2007). The Association for South African Women in Science and Engineering (SAWISE) also supports girls' education, particularly in the STEM fields at the post-secondary level (Anzia 2007). In 2007, Oprah Winfrey started a school in Johannesburg to provide South African girls living in poverty with a quality education, which drew a great deal of international attention (Anzia 2007). 


\section{Family Life}

Most South Africans live as part of a family unit, but the composition of the family unit reflects great within-country diversity. South Africans living in urban environments and with higher levels of education are more likely to live in nuclear families (Ameoteng et al. 2007). This arrangement is particularly common among Whites and Asians. Those with lower levels of education and in rural areas tend to live as an extended family unit, although it is becoming more common for well-educated and wealthy South Africans to also live as a large extended family (Ameoteng et al. 2007).

In some extended rural families, government pensions issued to seniors are shared with family members, especially if they are all living as members of the same household. The majority of elderly women in a qualitative study in rural South Africa reported engaging in the process of "pension sharing" with their unemployed children and grandchildren needing assistance, stretching their money to benefit as many family members as possible (Schatz and Ogunmefun 2007). Many of their grandchildren had been orphaned by the HIV/AIDS epidemic and had turned to their grandmothers as caretakers and sources of financial support.

In South Africa, marriages can take one of three forms: (a) civil or legal, (b) religious, or (c) customary or common law, which can be either monogamous or polygamous (Moore 2015). Both Black men and women in customary marriages tend to have both lower levels of education and lower income compared to Black South Africans in civil marriages (Moore 2015). There are gender differences regarding spousal cohabitation depending on whether one lives in an urban versus rural setting. In urban areas, men and women are equally likely to live in the same household with their spouse (Statistics South Africa 2013). In rural areas, married men are considerably more likely to live with their spouses than are married women.

One traditional African marital practice that has undergone a transition in light of globalization is the lobola, a dowry payment exchanged between the families of the bride and groom just before marriage (Khomari et al. 2012). Although in the past labola has signified the unification of two families, critics claim it is now used as a way for the bride's family to make money (Cekete 2008, as cited in Khomari et al. 2012). Furthermore, critics argue that it perpetuates patriarchal values and the idea that a wife is the property of her husband. South African university students echoed those concerns by explaining that lobola has become more of a business transaction than a symbolic joining of families, putting wives at risk for future victimization by their husbands (Khomari et al. 2012).

The changes in the social and political climate in South Africa since the end of the apartheid in 1994 have also impacted families, in large part because since that time women have been encouraged to participate in the workforce as the country moves toward gender equality (Spjeldnæs et al. 2014). Despite taking on additional work outside the home, South African women are still the primary caretakers of their children, as is frequently the case around the world (Akande et al. 2006). 
Regarding children's living arrangements, there is considerable within-country racial diversity. For example, while the overwhelming majority of Indian/Asian and White children live with both parents (83 and $73.8 \%$, respectively), more Black $(41.9 \%)$ and colored (33.9\% children live only with their mothers, Statistics South Africa 2013). This may be a vestige of apartheid when work passes were issued to one member of the family so that families were forcibly separated (South African Government 2016a, b).

Thus, there is no typical South African family. Living arrangements for spouses and children, the type of marriage, and who lives in the household are related to race, education, and income levels, as well as one's location (urban or rural).

\section{Work}

In downtown Johannesburg, Sthabil Mahlangu, a mother of four, hawks her wares, including hats, gloves, sweets, and cigarettes. She turned to street vending after she lost her job as a domestic worker. Like other participants in the informal economy, she lacks benefits and job security, and she is also at risk for being fined for selling in a public space (Timse 2009). Sibongile Sambo applied to be a flight attendant, but did not meet the height requirement. So she founded her own airline, SRS (Sibongile Rejoice Sambo) Aviation. Today her company provides private aviation services and also supports women who want to be pilots (Daftari and Patel 2016). Although both of these South African women are resilient and enterprising, their circumstances have led to very different job conditions.

In South Africa, women are increasingly entering the labor market, due in part to changing gender norms, increased wages, and technological advances in household tasks, allowing more time for paid work (Women Department Republic of South Africa 2015). As in other domains, the nature of work and its remuneration differ not only by gender, but also by race, education, and economic condition. Both occupational segregation (women and men concentrated in different occupations) and occupational stratification (men found in higher status and more lucrative positions than women) are prevalent. The latest labor report from South Africa shows that although White and Indian/Asian workers dominate the skilled occupations, within each racial group there are gender differences. For example, among Black Africans, $29 \%$ of men and $43 \%$ of women work in low-skilled occupations such as domestic work (Statistics South Africa 2016). Among White workers, 62\% of men and $58 \%$ of women work in skilled occupations, such as a manager or professional. Women are consistently more likely to be unemployed, or to be employed in private households or the informal sector. A detailed analysis from 2011 (Statistics South Africa 2013) revealed that Black African women were more likely than any other group to be discouraged work seekers $(8.9 \%)$, with lowest rates among White men $(<1 \%)$. Discrepancies by gender and ethnicity were also evident with respect to pay. Within each racial group, men earned more money than women (Statistics South Africa 2013). The hourly wage of White men was about 
four times that of Black African women and White women earned almost three times as much as Black African women.

In South Africa, as in all parts of the world, women do the majority of unpaid work. Among Black Africans, employed women spend an average of 266 min per day on unpaid housework, care of others, and collecting fuel and water, whereas employed men spend an average of 105 min per day on those tasks (Statistics South Africa 2011). All racial groups show significant gender differences, with women performing more unpaid work than men. Collecting water and fuel are tasks that are almost exclusively done by women worldwide (Waring and Steinem 1988). In South Africa the gender imbalance is exaggerated and women take on an even greater larger share when the distance to the water or fuel source is greater (Statistics South Africa 2013).

Despite demonstrable inequities, South African women are increasingly entering traditionally male-dominated occupations such as senior executive positions as well as positions in construction, engineering, mining, and the military (Mayer and Barnard 2015). Two qualitative studies have described the challenges they face in resisting traditional patriarchy. In the first study, five South African women (two Black, two White, and one Asian) who worked in traditionally male industries such as mining or engineering, reported organizational practices that discriminated against women (such as biased policies and gender-typed expectations) as well as difficulties with achieving a satisfactory work-life balance. The women countered those biases by using coping strategies such as mentorship, focusing on the work itself, and recognizing their own successes (Martin and Barnard 2013). In a second qualitative study, 13 South African Indian women who worked as managers described how they had learned as children to be obedient, respectful, modest, subservient, and passive (Carrim and Nkomo 2016). As managers they faced obstacles such as exclusion from informal networks, challenges to their authority and competence, and "a glass ceiling" that impeded their promotion to top positions. To overcome those barriers, they had to unlearn childhood socialization, as well as learn to work with men, become assertive, and manage conflict.

In sum, the great majority of South African women, from informal street traders and domestic workers to executives and managers, face discrimination in the workplace. Informal street traders like Sthabil Mahlangu live in a situation of vulnerability; they confront economic challenges, sociocultural barriers such as competition among traders, lack of technical and market knowledge, and regulations that limit or restrict their business (Willemse 2011). Domestic workers, although they make up almost $7 \%$ of the employed population, may suffer from exploitation with low wages, long hours, and unreasonable demands (Harrisberg 2015). And, as noted above, women in traditionally male or managerial positions also face challenges at work. 


\section{Adolescent Girls}

A developmental task of adolescence is forming romantic, and often sexual, relationships. Much of the research concerning adolescence in South Africa focuses on teenage sexuality, most likely because of its association with a risk for HIV/AIDS. Young South African women are three to four times as likely to contract HIV as their male counterparts (Shisana et al. 2014).

Research on sexuality and romance in South Africa has revealed that adolescents' conceptions and behavior are often rooted in gender-role stereotypes. In describing romance and intimacy, most South African adolescents described conventional, gender-typed, heterosexual romances that included male dominance and sometimes verbal and physical aggression (Lesch and Furphy 2013). The adherence to heterosexual gender-role stereotypes marginalizes the LGBT community. Despite the guarantee of equal rights for persons of all sexual orientations in the South African constitution, the reality is that gay and lesbian youth experience homophobia (Butler et al. 2003).

When describing relationships and sexuality, girls idealized virginity and respect (Bhana 2016b). They focused less on sexuality than did boys and to a greater extent on trust, love, decency, and relationship quality (Bhana 2016a). Teachers who taught sex education to South African teens also held stereotypic views of boys as predatory and girls as victims (DePalma and Francis 2014). Thus, well-meaning interventions may perpetuate gender-role stereotypes. Peers also held stereotypic views in that "masculine virility, the avoidance of shameful virgin or gay positions, and multiple sexual partners were emphasized for men, while the necessity of keeping a boyfriend and avoiding a 'slut' position were foregrounded for women" (Macleod and Jearey-Graham 2016, p. 230). In a retrospective study of sexual debuts, Stern and Cooper (2014) found that women had often felt pressured by their partners to have sex, reinforcing the stereotype that men are controlling and aggressive. Finally, in a study of attitudes about "taxi queens," girls who attached themselves to taxi drivers were considered by, adolescents ages 15-18 to be "sluts," (a common stereotype of sexually active women) (Strebel et al. 2013).

As holds true for many adolescent girls around the world, the lives of South African girls shrink at puberty (Arnett 2012; Hallman et al. 2015). By grades 8 and 9, access to public space for urban girls had shrunk to less than half the size of 5th graders, and to one-third that of their male peers (Hallman et al. 2015). Life space constriction is related to perceived (and real) danger of violence, particularly sex-related violence that girls may experience (De Vries et al. 2014; Hallman et al. 2015).

Although South African girls face risks such as exposure to HIV/AIDS, intimate partner violence, and restriction of life space, there is evidence of their resilience and hope. The ideal woman "is working very hard to get somewhere in life," wrote a 13-year-old South African girl (Gibbons and Stiles 2004, p. 29). Another wrote that the ideal woman "needs to be kind and honest and must be willing to help those in need" (Gibbons and Stiles 2004, p. 35). Like adolescents around the world, South African teenage girls highly valued kindness, honesty, affection toward 
children, and hard work in the ideal woman. They also thought that she should be fun loving (Gibbons and Stiles 2004).

South African teenage girls also expressed high levels of hope for success and a better future (Abler et al. 2016). Hope serves as a psychosocial strength that can help protect girls from anxiety, depression, and risky sexual behaviors. Hope, altruism, and community connectedness emerged as themes in another South African study in which adolescents described those resiliencies that allowed them to combat daily stressors and harsh living conditions (Mosavel et al. 2015).

\section{Challenges and Risks to South African Women}

\section{Poverty}

"Women in South Africa are still the face of poverty" (African National Congress [ANC] 2014, p. 2). Given women's lower levels of paid employment, greater household responsibilities, and lower hourly wages, it is not surprising that women in South Africa are more likely than their male counterparts to live in poverty. Women are poorer than men whether poverty is calculated as income per individual, income per household, a comparison of female-headed versus male-headed households, or measured by a multidimensional index that takes into account deprivation in areas such as child mortality, education, nutrition, sanitation, and water (Rogan 2014, 2016). Even when income is adjusted for lower consumption by children and for economies of scale, there is still a significant gender gap in poverty (Posel et al. 2016). Although overall levels of poverty have declined in South Africa since 1993, the gender gap has widened (Rogan 2014, 2016).

Poverty may also be experienced differently by women and men (Bentley 2004). Because women more often support and protect children, poverty may pose additional risks to their well-being. For example, women may restrict their own food intake in favor of children's nutrition, and in patriarchal households, women and girls may be allocated less nutritious food (ANC 2014).

Moreover, poverty is unequally distributed. Women living in rural areas are more likely than those living in urban settings to be poor (Kehler 2001; Women Department Republic of South Africa 2015). Because land ownership is crucial to economic sufficiency in farming areas, women may be disadvantaged by lack of assets, including land (Women Department Republic of South Africa 2015). Poverty is also unequally distributed by racial group. Black African rural women are especially likely to be unemployed and poor (53\% unemployment as compared to 5\% for rural White women). In 2012, 63\% of Black African women, 35\% of "Colored" women, and $1.6 \%$ of White women were living below the poverty line (Women Department Republic of South Africa 2015). From 2008 to 2012 the poverty rate of Black African Women did not change, that of Colored women increased, and that of 
White women decreased (Women Department Republic of South Africa 2015). Thus, decreases in poverty are benefitting an already advantaged segment of the population.

Poverty is often associated with diminished well-being and quality of life; it is also linked to violence and susceptibility to health challenges such as HIV/AIDS (Bentley 2004). Many argue that the path out of poverty lies in society's fostering the greater empowerment of women to promote sustainable growth (Diop 2015; Women Department Republic of South Africa 2015).

\section{Health}

HIV/AIDS. The core of the HIV/AIDS epidemic resides in South Africa. Although the country has only .7\% of the world's population, $19 \%$ of all HIV cases worldwide are located in South Africa (Central Intelligence Agency [CIA] 2016; Karim et al. 2009). By 2015, there were 7 million South Africans living with HIV (Avert 2016). Across all age groups, $56 \%$ of the HIV/AIDS population in South Africa are women or girls (ONE 2015). In order to understand the scope of this epidemic, insight into apartheid South Africa is useful. Many men lived in overcrowded spaces in urban areas that were frequently visited by prostitutes aptly called "town-wives" (Karim et al. 2009). These men then returned home on occasion to visit their wives living in rural areas. These conditions coupled with historic poor access to health care for Black South Africans has facilitated the spread of HIV (Karim et al. 2009).

Young South African women have suffered disproportionally with respect to HIV infection. For example, a quarter of all new HIV infections reported in South Africa in 2012 occurred in women ages 15-24 (Avert 2016). Despite such a high rate, however, the number of new HIV infections reported in this age group has actually been on the decline. The higher infection rate of women can be attributed to a variety of causes in which women are at a disadvantage: poverty (women are more likely to live in poverty than men), gender-based violence (women are more likely to be victims than men), and low social power (women tend to have lower social power compared to men; Avert 2016).

As a result of recent efforts, women have been able to receive HIV testing as part of their routine prenatal doctor's visits with testing rates for women rising more drastically than for men from 2008 to 2012 (Avert 2016). This initiative resulted in 95\% of all pregnant HIV-positive women receiving medication to reduce the risk of transmitting HIV to her baby (AIDS Vaccine Advocacy Coalition [AVAC] 2014; Avert 2016).

A qualitative study with HIV-positive South African women revealed that after managing the initial shock of their diagnosis, many found the available antiretroviral treatments to be useful in managing their illness and regaining control over their lives (Wouters and De Wet 2016). The women were diagnosed during the time of apartheid and were living in poverty, thus compounding the negative implications and consequences of their diagnosis. 
Unfortunately, in spite of medical advances that make it possible for people to live longer with HIV/AIDS and the implementation of the Promotion of Equality and Prevention of Unfair Discrimination Act (PEPUDA) in 2000, the stigma of living with the disease in South Africa remains difficult to manage (AVAC 2014). Many women employed outside the home feared the stigma that could result upon revealing their HIV status to their employers (Wouters and De Wet 2016). Learning one has HIV also means that they are vulnerable to stigmatization when expressing their desire to practice safe sex (Wouters and De Wet 2016). One woman argued stigma should be reduced, however, because advances in treatment ensure an HIV diagnosis is no longer a death sentence (Wouters and De Wet 2016).

Maternal health. Many of the issues pertaining to maternal health in South Africa are related to HIV/AIDS and the potential for transmission of the virus from the mother to her baby. A recent UNICEF report indicated that the country is making promising strides in maternal health (UNICEF 2014/2015). For example, in 2012-2013, the transmission of HIV from mother to child was reduced to $2.6 \%$ (UNICEF 2014/2015). This number has dropped to $1.5 \%$ in 2015. Infant and maternal mortality have also been decreasing. For example, there were 46 infant deaths per 1000 live births in 1995, compared to 15 in 2012 (Mayosi and Benatar 2014); maternal deaths dropped from 3.20 per 1000 births in 2009 to 1.38 in 2015 (CIA 2016; Pattinson 2015).

Attitudes toward adolescent pregnancy in South Africa are evolving. Just 20 years ago in the 1990s, teenage pregnancy was acceptable in South Africa; it was particularly normalized in Black communities (Nicholson 2016). Adolescent girls themselves seem to hold contradictory views of teenage pregnancy with some recognizing the challenges it brings and others claiming it is a social good (Nicholson 2016). Nowadays, however, adolescent motherhood is becoming more stigmatized, often bringing shame to family members. Statistics mirror this pattern of changing attitudes with rates of teenage pregnancy on the decline in recent years with 78 of every 1000 babies in 1996 born to adolescent mothers compared to 54 per 1000 babies in 2007 (UNICEF South Africa 2009).

Poverty, race, academic performance, and an imbalance of power between the girl and her sexual partner are related to rates of teen pregnancy (UNICEF South Africa 2009). For example, Black and Colored youth are more likely to become adolescent mothers than White or Asian young women (UNICEF South Africa 2009). Furthermore, experts point to infrequent, inconsistent contraceptive use despite knowledge of available methods to partially explain the high rates of adolescent pregnancy in the country (UNICEF South Africa 2009). In more rural areas (e.g., Matjitjileng Village in the Limpopo province), it may be considered inappropriate to talk with young people about sex suggesting that the infrequent contraceptive use can be traced to a lack of sex education (Thobejane 2015). As in other countries, consequences for the young mother include an increased risk of economic hardship.

Body image and disordered eating. Body image and disordered eating are health-related concerns that primarily affect women. Although initially considered more problematic in the West, where the thin ideal is endorsed, body image and 
eating disorders are becoming more prevalent in diverse groups as they become increasingly exposed to international media via globalization (Carney and Louw 2006). Female South African university students as well as those who reported greater exposure to the ideal body image promoted in the media were at greater risk for developing anorexia nervosa than male students and females with lower levels of media exposure (Carney and Louw 2006).

To better understand these patterns, young women were interviewed about their media use and their definition of an ideal body type. Their responses indicated that ideally one is tall, thin, and proportional. Models and celebrities with this body type were admired, while those who were overweight were scorned. The young women did note, however, that there were limits to the attractiveness of thinness and that some of the celebrities were too thin, making them look unhealthy. While some of the young women reported a more critical, engaged approach to consuming media by noting when photos appeared to have been retouched, others shared that they consumed media in an addictive, obsessive manner. Several participants did report unhealthy dieting behaviors to try to achieve the thin ideal with some even admitting to starving themselves to achieve a thinner physique.

A more recent qualitative study with Black South African adolescent girls revealed interesting racial and ethnic preferences with respect to body image, providing a more nuanced perspective of the ideal body and disordered eating (Morris and Szabo 2013). Interestingly, even in the consent process, parents were hesitant to provide permission for their daughters' participation because they viewed issues of body image and disordered eating as a "white women's disorder" (Morris and Szabo 2013, p. 339). Many of the girls did endorse a traditional Western ideal of thinness, noting that it was easier to find fashionable clothes in smaller sizes. However, others valued the traditional ideal of plumpness, serving as a reminder that the ideal body image and attractiveness are culturally constructed. In diverse schools with both White and Black students, the Black youth indicated that much of their stress about body image came from their White peers' preoccupations with their own weight

White girls are obsessed about their weight and we spend a lot of time with them, so we start comparing ourselves to them and that is where the pressure is coming from. We think if SHE is fat, then what am I? (Morris and Szabo 2013, p. 340).

The findings of another quantitative study revealed the complexity of the factors contributing to eating disorders among White and Black South African adolescent girls (Gitau et al. 2014). Although White adolescent girls were much more likely to desire a lower weight, the Black adolescents were more at risk for developing an eating disorder based on a self-report measure, reported more body dissatisfaction, and were more likely to restrict their eating compared to White peers. However, the Black girls had lower body mass index (BMI) scores and higher self-esteem; they thought heavier women were more attractive. These conflicting results of a higher susceptibility for an eating disorder in Black girls despite a heavier ideal and high 
self-esteem, yet an overwhelming desire for thinness in White girls are inconsistent with most theories of eating disorders and suggest that contradictory messages that South African youth receive from the media and their cultures have complex implications for their attitudes and behaviors.

\section{Violence Against Women}

Violence against women in South Africa is best understood in the context of the country's history of colonialism and apartheid (Vetten 2000). As described earlier, despite progressive legislation in the post-apartheid era, patriarchal values are still present in South Africa. Patriarchy is a system in which men are seen as the unquestioned authority and hold power over women (Park et al. 2000). It is important to note that violence has historically been viewed as an acceptable way to solve problems in South African society (Abrahams and Jewkes 2005). Violence is often viewed as a normative, permissible outlet to express anger and exert authority (Abrahams and Jewkes 2005). Patriarchal attitudes, then, combined with a propensity for violence, could mean a heightened risk of victimization for women.

The Domestic Violence Act (Act 116) was introduced in 1998 in South Africa (Park et al. 2000). The Act requires law enforcement to protect victims of interpersonal violence and abuse, which can include physical and sexual assault, emotional and psychological abuse, stalking, and harassment (Moletsane-Kekae 2009; Park et al. 2000). South Africa's participation in the international 16 Days of Activism for No Violence Against Women and Children campaign since 1998 is another governmental effort to discourage violence and encourage gender equality (South African Government 2016a). Taking place from November 15 to December 10 each year, the campaign serves as a reminder to communities of their responsibility to stand up to violence as well as to the individual to denounce and reduce violence. Finally, the government is particularly committed to abolishing ukuthwala, a practice in which a girl is kidnapped by a man to force either the girl of her family to agree to marriage (South African Government 2016b).

Despite those governmental and legislative efforts to address violence against women, the government of South Africa still recognizes gender-based violence as a key, ongoing issue for the country (South African Government 2016a, b). South Africa's Thuthuzela Care Centres are internationally recognized for their comprehensive approach to treating victims of rape and other sexual assault crimes (UNICEF South Africa, n.d.c; South African Government 2016b). The word "Thuthuzuela," meaning "comfort" in Xhosa, aptly describes these care centers, which operate inside public hospitals and provide both medical and psychological treatment (UNICEF South Africa, n.d.c). The care extends beyond the initial visit as professionals accompany women through the legislative process of prosecuting their offenders and work with special sexual offense courts to enforce rape prevention (UNICEF South Africa, n.d.c). 
A qualitative study with nine South African women who had been victims of domestic violence revealed the causes of the maltreatment, the types of abuse the women endured, their rationale for staying in those relationships, and the critical assistance the participants received from women's shelters after they left their abusive partners (Moletsane-Kekae 2009). According to those women, the source of the mistreatment could be traced to one of five causes: (a) Women refused to have sex without a condom, (b) Women would not allow their partners to have extramarital affairs, (c) Women refused to give their perpetrators money to buy drugs, (d) Women refused to be isolated from their friends and relatives, and (e) Women refused to have sex with perpetrators who demanded sex anytime they wanted it because they had paid lobola, or a dowry. Some of the perpetrators even demanded that their wives skip lunchtime at work to go home and have sex with their unemployed spouses.

These women recalled various types of abuse such as verbal, emotional/psychological, physical, sexual, and financial abuse. Women were shouted at, ridiculed, degraded, falsely blamed, and humiliated by their abusers. Some endured death threats directed not only at them but also at their children, family members, and friends. One woman reported that after refusing to remain isolated from her family and friends, her fiancé shot her in the head. When another participant insisted on her partner using a condom, he replied that he did not want his children to suffocate in a plastic bag (i.e., the condom), and refused to use one, thereby blatantly disrespecting his partner's wishes to have protected sex.

When asked to explain why the women had stayed in the abusive relationships, participants cited a variety of reasons ranging from economic dependence, to protection of their family members, to concerns about their reputation (e.g., being known as a coward). Some women were mindful of the cultural custom, "lebitla le mosadi ke bogadi - in seSotho", the idea that women may not divorce their husbands. Instead, wives may only be separated from husbands by death.

Once the women were able to leave their husbands, they found refuge in a women's shelter. The benefits were numerous for the victims, but a central one was that the women were empowered to regain control of their lives. Two women who were HIV-positive began receiving treatment, while others found solace in the support embedded within the shelter community. Several of the women even hoped to serve as future counselors for other victims of domestic violence.

\section{Programs to Better Women's Lives}

Numerous programs exist to address the needs of South African women presented in this chapter. However, as is oftentimes the case, the majority of those programs are not systematically and empirically evaluated. Below we provide two examples of evidence-based programs that aim to empower women and girls.

In an intervention to reduce poverty and interpersonal violence and foster empowerment, women ages 18-96 in South Africa's Limpopo province participated in a microfinance program and simultaneously received training on topics like 
sexual health and domestic violence (Kim et al. 2007). Many participants reported a history of physical and/or sexual abuse. Microfinance programs have been used internationally to provide people (oftentimes women) with loans to start businesses that will yield future income (Kim et al. 2007). A matched pair's waitlist control group design was used; four villages participated in the experimental group and another four in the waitlist control group.

Participants' scores on all nine measures of empowerment showed post-intervention improvement. Empowerment measures included: "self-confidence, financial confidence, challenging gender norms, autonomy in decision-making, perceived contribution to the household, communication with the household, relationship with partner, social group membership, and participation in a collective action" (Kim et al. 2007, p. 1796). In the year following the intervention, participants' reports of IPV decreased by more than $50 \%$. In the control groups, IPV rates either increased or remained consistent suggesting the intervention had both attitudinal and behavioral benefits.

To address HIV prevention in adolescent girls, Hershow et al. (2015) created an intervention centered around soccer to boost adolescent girls' self-efficacy, to increase HIV-related knowledge, and to encourage participation in HIV counseling. The program, called SKILLZ Street (SS), is a sports-based after-school HIV prevention program designed especially for girls. Girls participated in 10 sessions of $2 \mathrm{~h}$ each during which they played soccer, learned life skills, and took advantage of HIV counseling services. Girls were able to play in a non-competitive environment while life skills topics ranged from body image to HIV to romantic relationships. The design was a simple pretest/posttest design without random assignment or a control group.

Girls not only reported quantitative improvements in their communication skills about HIV and other topics, but also revealed more egalitarian views on gender. For example, participants were more likely to say that "A girl's opinion is just as important as a guy's" at posttest compared to pretest (Hershow et al. 2015, p. 1016). Focus group data with the girls revealed many of the same benefits. For example, participants noted that personally having the chance to play soccer helped to change their gender-stereotyped attitudes that soccer was only for boys. Furthermore, the coach-player rapport was excellent; in many cases, the coaches served as mentors and sources of trusted guidance and support about a multitude of challenges the girls faced in their daily lives. Finally, the availability of HIV testing and counseling services as part of the program helped educate girls about methods of HIV prevention.

\section{Conclusion}

The lives of South African girls and women are characterized by intersectionality; their experiences in the realms of education, work, and family differ by economic status, race, ethnicity, age, rural-urban residence, and health status. Risks of 
experiencing poverty, HIV/AIDS, and violence are intertwined and all too prevalent. However, they are countered by the influence of "rocks" representing the strength and resilience of South African women.

\section{References}

Abler, L., Hill, L., Maman, S., DeVellis, R., Twine, R., Kahn, K. ... Pettifor, A. (2016). Hope matters: Developing and validating a measure of future expectation among young women in a high HIV prevalence setting in rural South Africa (HPTN 068). AIDS and Behavior. Advance online publication. doi:10.1007/s10461-016-1523-6

Abrahams, N., \& Jewkes, R. (2005). Effects of South African men having witnessed abuse of their mothers during childhood on their levels of violence in adulthood. American Journal of Public Health, 95(10), 1811-1816. doi:10.2105/AJPH.2003.035006

African National Congress. (2014). Women and poverty discussion document. Retrieved from http://www.anc.org.za/docs/discus/2014/women_povertyj.pdf

AIDS Vaccine Advocacy Collation. (2014). For women in South Africa, HIV stigma still runs strong. Retrieved from http://www.avac.org/blog/women-south-africa-hiv-stigma-still-runsstrong

Akande, A., Adetoun, B., \& Tserere, M. (2006). The South African family. In J. Georgas, J. W. Berry, F. J. R. Van de Vijver, Ç. Kağitcibąsi, \& Y. Poortinga (Eds.), Families across cultures: A 30-nation psychological study (pp. 442-449). Cambridge, UK: Cambridge University Press.

Ameoteng, A. Y., Heaton, T. B., \& Kalule-Sabiti, I. (2007). Living arrangements in South Africa. In A. Y. Ameoteng \& T. B. Heaton (Eds.), Families and households in post-apartheid South Africa: Socio-demographic perspectives (pp. 43-60). Cape Town, South Africa: HSRC Press.

Anzia, L. (2007). "Educate a woman, educate a nation"-South Africa aims to improve its education for girls. Retrieved from https://womennewsnetwork.net/2007/08/28/educate-awoman-you-educate-a-nation-south-africa-aims-to-improve-its-education-for-girls/

Arnett, J. J. (2012). Adolescence and emerging adulthood: A cultural approach (5th ed.). Upper Saddle River, NJ: Prentice-Hall.

Avert. (2016). HIV and AIDS in South Africa. Retrieved from http://www.avert.org/professionals/ hiv-around-world/sub-saharan-africa/south-africa

Bentley, K. (2004). Women's human rights \& the feminisation of poverty in South Africa. Review of African Political Economy, 31(100), 247-261. http://www.jstor.org/stable/4006890

Bhana, D. (2016a). 'Sex isn't better than love': Exploring South African Indian teenage male and female desires beyond danger. Childhood, 23, 362-377. doi:10.1177/09075568216642828

Bhana, D. (2016b). Virginity and virtue: African masculinities and femininities in the making of teenage sexual cultures. Sexualities, 19, 465-481. doi:10.1177/1363460715613298

Bhorat, H. (2015). Is South Africa the most unequal society in the world? Retrieved from http:// mg.co.za/article/2015-09-30-is-south-africa-the-most-unequal-society-in-the-world

Bower, C. (2014). The plight of women and children: Advancing South Africa's least privileged. The Annals of the American Academy of Political and Social Science, 652, 106-126.

Butler, A. H., Alpaslan, A. H., Strümpher, J., \& Astbury, G. (2003). Gay and lesbian youth experiences of homophobia in South African secondary education. Journal of Gay \& Lesbian Issues in Education, 1(2), 3-28. doi:10.1300/J367v01n02_02

Carney, T., \& Louw, J. (2006). Eating disordered behaviors and media exposure. Social Psychiatry and Psychiatric Epidemiology, 41, 957-966. doi:10.1007/s00127-006-0120-9

Carrim, N. M. H., \& Nkomo, S. M. (2016). Wedding intersectionality theory and identity work in organizations: South African Indian women negotiating managerial identity. Gender, Work and Organization, 23(3), 261-277. doi:10.1111/gwao.12121 
Central Intelligence Agency. (2016). World factbook: South Africa. Retrieved from https://www. cia.gov/library/publications/the-world-factbook/geos/sf.html

Claassens, A., \& Mnisi, S. (2009). Rural women redefining land rights in the context of living customary law. South African Journal on Human Rights, 25, 491-516.

Daftari, A., \& Patel, H. (2016). The rejected flight attendant who started her own aviation company. Retrieved from http://www.cnn.com/2016/02/03/africa/sibongile-sambo-srsaviation-feat/

DePalma, R., \& Francis, D. A. (2014). The gendered nature of South African teachers' discourse on sex education. Health Education Research, 29, 624-632. doi:10.1093/her/cyt117

De Vries, H., Eggers, S. M., Jinabhai, C., Meyer-Weitz, A., Sathiparsad, R., \& Taylor, M. (2014). Adolescents' beliefs about forced sex in KwaZulu-Natal, South Africa. Archives of Sexual Behavior, 43, 1087-1095. doi:10.1007/s10508-014-0280-8

Diop, M. (2015). How empowering women can help end poverty in Africa. Retrieved from http:// blogs.worldbank.org/nasikiliza/how-empowering-women-can-help-end-poverty-africa

Gibbons, J. L., \& Stiles, D. A. (2004). The thoughts of youth: An international perspective on adolescents' ideal persons. Greenwich, CT: Information Age Publishing.

Gitau, T. M., Micklesfield, L. K., Pettifor, J. M., \& Norris, S. A. (2014). Ethnic differences in eating attitudes, body image and self-esteem among adolescent females living in urban South Africa. Journal of Psychiatry, 17, 468-474. doi:10.4172/Psychiatry.1000101

Government of South Africa. (1996, January 15). Bill of Rights (Chapter 2 of the Constitution of the Republic of South Africa). Retrieved from https://www.westerncape.gov.za/legislation/billrights-chapter-2-constitution-republic-south-africa

Grant, E. (2006). Human rights, cultural diversity, and customary law in South Africa. Journal of African Law, 50, 2-23. http://dx.doi.org/10.1017/S0021855306000039

Hallman, K. K., Kenworthy, N. J., Diers, J., Swan, N., \& Devnarain, B. (2015). The shrinking world of girls at puberty: Violence and gender-divergent access to the public sphere among adolescents in South Africa. Global Public Health, 10, 279-295. doi:10.1080/17441692.2014. 964746

Harrisberg, K. (2015). The struggle for a fair wage: Living on the edge. Retrieved from http:// livingwage.code4sa.org

Hershow, R. B., Gannett, K., Merrill, J., Kaufman, E. B., Barkley, C., DeCelles, J., et al. (2015). Using soccer to build confidence and increase HCT uptake among adolescent girls: A mixed-methods study of an HIV prevention programme in South Africa. Sport in Society: Cultures, Commerce, Media, Politics, 18, 1009-1022. doi:10.1080/17430437.2014.997586

Karim, S. S. A., Churchyard, G. J., Karim, Q. A., \& Lawn, S. D. (2009). HIV infection and tuberculosis in South Africa: An urgent need to escalate the public health response. Lancet, 374, 921-933. doi:10.1016/S0140-6736(09)60916-8

Kehler, J. (2001). Women and poverty: The South African experience. Journal of International Women's Studies, 3(1), 41-53.

Khomari, D. M., Tebele, C., \& Nel, K. (2012). The social value of lobola: Perceptions of South Africa college students. Journal of Psychology in Africa, 22, 143-145.

Kim, J. C., Watts, C. H., Hargreaves, J. R., Ndhlovu, L. X., Phetia, G., Morison, L. A. ... Pronyl, P. (2007). Understanding the impact of microfinance-based intervention on women's empowerment and the reduction of intimate partner violence in South Africa. American Journal of Public Health, 97, 1794-1802. doi:10.2105/AJPH.2006.095521

Lesch, E., \& Furphy, C. (2013). South African adolescents' constructions of intimacy in romantic relationships. Journal of Adolescent Research, 28, 619-641. doi:10.1177/074355841340835

Macleod, C. I., \& Jearey-Graham, N. (2016). "Peer pressure" and "peer normalization": Discursive resources that justify gendered youth sexualities. Sex Research and Social Policy, 13, 230-240. doi:10.1007/s13178-015-0207-8

Martin, P., \& Barnard, A. (2013). The experience of women in male-dominated occupations: A constructivist grounded theory inquiry. SA Journal of Industrial Psychology, 39(2), 1-12. doi:10.4102/sajip.v39i2.1099 
Mayer, C.-H., \& Barnard, A. (2015). Balancing the scales of gender and culture in contemporary South Africa. In S. Safdar \& N. Kosakowska-Berezecka (Eds.), Psychology of gender through the lens of culture (pp. 327-349). New York, NY: Springer.

Mayosi, B. M., \& Benatar, S. R. (2014). Health and health care in South Africa-20 years after Mandela. The New England Journal of Medicine, 371, 1344-1353. doi:10.1056/ NEJMsr1405012

Moeti, K. (2012). South Africa: Girls need more than 'access' to education. Retrieved from http:// www.asafeworldforwomen.org/children/ch-africa/cr-south-africa/2481-education.html

Moletsane, R. (2011). Gender review in South African basic education. Retrieved from http:// www.ungei.org/paris2011/docs/GenderReviewFinalReportRevisedNov23.pdf

Moletsane-Kekae, M. (2009). The experiences of abused South African Women in shelters. Asian Women, 25, 49-68. doi:10.14431/aw.2009.06.25.2.49

Moore, E. (2015). Forms of femininity at the end of a customary marriage. Gender \& Society, 29, 817-840. doi:10.1177/0891243215599646

Morris, P. F., \& Szabo, C. P. (2013). Meanings of thinness and dysfunctional eating in black South Africa females: A qualitative study. African Journal of Psychiatry, 16, 338-342. doi:10.4314/ ajpsy.v16i5.45

Mosavel, M., Ahmed, R., Ports, K. A., \& Simon, C. (2015). South African, urban youth narratives: Resilience within community. International Journal of Adolescence and Youth, 20, 245-255. doi:10.1080/02673842.2013.785439

Mubangizi, J. C. (2012). A South African perspective on the class between culture and human rights, with particular reference to gender-related cultural practices and traditions. Journal of International Women's Issues, 13, 33-48.

Nedu. (n.d.). Top 10 richest women in South Africa. Retrieved from http://buzzsouthafrica.com/ top-10-richest-women-in-south-africa/

Nicholson, A, (2016). Babies for bling: How teenage pregnancy became emblematic of misspent youth in South Africa. Retrieved from http://www.research.uct.ac.za/babies-bling-howteenage-pregnancy-became-emblematic-misspent-youth-south-africa

ONE. (2015). Status of women and girls in South Africa 2015. Towards the United Nation General Assembly meeting on the new Sustainable Development Goals (SDGs). Retrieved from https:// s3.amazonaws.com/one.org/pdfs/Status-of-women-and-girls-in-South-Africa-2015.pdf

Park, Y. J., Fedler, J., \& Dangor, Z. (2000). Reclaiming women's spaces. New perspectives on violence against women and sheltering in South Africa. Johannesburg, South Africa: Nisaa Institute for Women Development.

Pattinson, R. (2015). South Africa's maternal mortality rate is on the road to recovery. Retrieved from http://theconversation.com/south-africas-maternal-mortality-rate-is-on-theroad-to-recovery-40272

Posel, D., Casale, D., \& Grapsa, E. (2016). Re-estimating gender differences in income in South Africa: The implications of equivalence scales. Development Southern Africa, 33(4), 425-441. doi:10.1080/0376835X.2016.1179105

Rogan, M. (2014). Poverty may have declined, but women and female-headed households still suffer most. Retrieved from http://www.econ3x3.org/article/poverty-may-have-declined-women-andfemale-headed-households-still-suffer-most

Rogan, M. (2016). Gender and multidimensional poverty in South Africa: Applying the global multidimensional poverty index (MPI). Social Indicators Research, 26, 987-1006. doi:10. 1007/s11205-015-0937-2

Schatz, E., \& Ogunmefun, C. (2007). Caring and contributing: The role of older women in rural South Africa multi-generational households in the HIV/AIDS era. World Development, 35, 1390-1403. doi:10.1016/j.worlddev.2007.04.004

Shisana, O., Rehle, T., Simbayi, L. C., Zuma, K., Jooste, S., Zungu N., et al. (2014) South African national HIV prevalence, incidence and behaviour survey, 2012. Cape Town, South Africa: HSRC Press. Retrieved from http://www.hsrc.ac.za/uploads/pageContent/4565/SABSSM\% 20IV\%20LEO\%20final.pdf 
South African Government. (2016a). 16 days of activism for no violence against women and children. Retrieved from http://www.gov.za/16-days-activism-no-violence-against-womenand-children-2014

South African Government. (2016b). Violence against women and children. Retrieved from http:// www.gov.za/issues/violence-against-women-and-children-0

South African History Archive. (2016). You strike the women, you strike the rock. Retrieved from http://www.saha.org.za/women/national_womens_day.htm

South African History Online. (2016). The history of separate development in South Africa. Retrieved from http://www.sahistory.org.za/article/history-separate-development-south-africa

Spjeldnæs, I. O., Molan, K. M., Harris, J., \& Sam, D. L. (2014). Mothering in Limpopo, South Africa: Perspectives of adolescents. Psychology \& Society, 57-77.

Statistics South Africa. (2011). Gender statistics South Africa, 2011. Retrieved from http://www. statssa.gov.za/publications/Report-03-10-05/Report-03-10-052011.pdf

Statistics South Africa. (2012). Census 2011. Retrieved from http://www.statssa.gov.za/ publications/P03014/P030142011.pdf

Statistics South Africa. (2013). Gender statistics in South Africa, 2011. Retrieved from http:// www.statssa.gov.za/publications/Report-03-10-05/Report-03-10-052011.pdf

Statistics South Africa. (2015). General household survey 2014. Retrieved from http://www. statssa.gov.za/publications/P0318/P03182014.pdf

Statistics South Africa (2016). Quarterly labour force survey quarter 3: 2016. Retrieved from http://www.statssa.gov.za/publications/P0211/P02113rdQuarter2016.pdf

Stern, E., \& Cooper, D. (2014). Experiences and conceptualization of sexual debut from the narratives of South African men and women in the context of HIV/AIDS. African Journal of AIDS Research, 13, 121-131. doi:10.2989/16085906.2014.943252

Strebel, A., Shefer, T., Potgieter, C., Wagner, C., \& Shabalala, N. (2013). 'She's a slut...and it's wrong': Youth constructions of taxi queens in the Western Cape. South African Journal of Psychology, 43, 71-80. doi:10.1177/0081246312474415

Thobejane, T. D. (2015). Factors contributing to teenage pregnancy in South Africa: The case of Matjitjileng village. Journal of Sociology and Social Anthropology, 6, 273-277.

Timæus, I. M., Simelane, S., \& Letsoalo, T. (2013). Poverty, race, and children's progress at school in South Africa. The Journal of Development Studies, 49, 270-284. doi:10.1080/ 00220388.2012 .693168

Timse, T. (2009). Unemployment forces many to street trading. Retrieved from http://mg.co.za/ article/2009-08-02-unemployment-forces-many-to-street-trading

Underhill, G. (2015, January 30). The trials of child-headed families. Retrieved from http://mg.co. za/article/2015-01-30-00-the-trials-of-child-headed-families

UNICEF. (2013). South Africa statistics. Retrieved from https://www.unicef.org/infobycountry/ southafrica_statistics.html

UNICEF. (2014/2015). Biennial report South Africa. Retrieved from https://www.unicef.org/ southafrica/SAF_resources_biennialreport14_15.pdf

UNICEF South Africa. (2009). Teenage pregnancy in South Africa; With a specific focus on school-going learners. Retrieved from http://www.education.gov.za/Portals/0/Documents/ Reports/Teenage\%20Pregnancy\%20Report,\%2028\%20August\%202009.pdf?ver=2011-01-18$113756-500$

UNICEF South Africa. (n.d.a). Girls \& boys education movement. Retrieved from https://www. unicef.org/southafrica/education_4718.html

UNICEF South Africa. (n.d.b). Overview: Education and adolescent development. Retrieved from https://www.unicef.org/southafrica/education_344.html

UNICEF South Africa. (n.d.c). Thuthuzela care centres. Retrieved from https://www.unicef.org/ southafrica/hiv_aids_998.html

Vetten, L. (2000). Gender, race and power dynamics in the face of social change: Deconstructing violence against women in South Africa. In Y. J. Park, J. Fedler, \& Z. Dangor (Eds.), Reclaiming women's spaces new perspectives on violence against women and sheltering in South Africa (pp. 7-406). Johannesburg, South Africa: Nissa Institute for Women's Development. 
Waring, M., \& Steinem, G. (1988). If women counted: A new feminist economics. San Francisco, CA: Harper \& Row.

Willemse, L. (2011). Opportunities and constraints facing informal street traders: Evidence from four South African cities. Town and Regional Planning, 59, 7-15.

Women Department Republic of South Africa. (2015). The report on the status of women in the South African economy. Retrieved from http://www.gov.za/sites/www.gov.za/files/Status_of_ women_in_SA_economy.pdf

World Bank Group. (2016). Gini index (World Bank estimate). Retrieved from http://data. worldbank.org/indicator/SI.POV.GINI?locations $=\mathrm{ZA}$

World Economic Forum. (2015). The global gender gap report 2015. Retrieved from http:// www3.weforum.org/docs/GGGR2015/The\%20Global\%20Gender\%20Gap\%20Index\% 202015.pdf

Wouters, E., \& De Wet, K. (2016). Women's experience of HIV as a chronic illness in South Africa: Hard-earned lives, biographical disruption, and moral career. Sociology of Health \& Illness, 38, 521-542. doi:10.1111/1467-9566.12377

\section{Suggested Readings and Resources for Further Study}

African National Congress. (2014). Women and poverty discussion document. Retrieved from http://www.anc.org.za/docs/discus/2014/women_povertyj.pdf

Mayosi, B. M., \& Benatar, S. R. (2014). Health and health care in South Africa-20 years after Mandela. The New England Journal of Medicine, 371, 1344-1353. doi:10.1056/ NEJMsr1405012

Moletsane-Kekae, M. (2009). The experiences of abused South African Women in shelters. Asian Women, 25, 49-68. doi:10.14431/aw.2009.06.25.2.49

ONE. (2015). Status of women and girls in South Africa 2015. Towards the United Nation General Assembly meeting on the new Sustainable Development Goals (SDGs). Retrieved from https:// s3.amazonaws.com/one.org/pdfs/Status-of-women-and-girls-in-South-Africa-2015.pdf

UNICEF. (2014/2015). Biennial report South Africa. Retrieved from https://www.unicef.org/ southafrica/SAF_resources_biennialreport14_15.pdf

Women Department Republic of South Africa. (2015). The report on the status of women in the South African economy. Retrieved from http://www.gov.za/sites/www.gov.za/files/Status_of_ women_in_SA_economy.pdf 